\title{
Corporate Criminal Law and Organization Incentives: A Managerial Perspective*
}

\author{
Nuno GAROUPA ${ }^{\dagger}$ \\ Universitat Pompeu Fabra, \\ Spain
}

November 2000

\begin{abstract}
Corporate criminal liability puts a serious challenge to the economic theory of enforcement. Are corporate crimes different from other crimes? Are these crimes best deterred by punishing individuals, punishing corporations, or both? What is optimal structure of sanctions? Should corporate liability be criminal or civil?

This paper has two major contributions to the literature. First, it provides a common analytical framework to most results presented and largely discussed in the field. In second place, by making use of the framework, we provide new insights into how corporations should be punished for the offenses committed by their employees.
\end{abstract}

Keywords: law enforcement, corporation JEL classification: K4.

*Financial support by CICYT (grant SEC99-1191-C02-01) is gratefully acknowledged. The usual disclaimers apply.

$\dagger$ Department d'Economia i Empresa, Universitat Pompeu Fabra, Ramon Trias Fargas 25-27, 08005 Barcelona, Spain. Email: nuno.garoupa@econ.upf.es; Phone: +34-935422639; Fax: +34-93-5421746 


\section{Introduction}

In the United States, but generally not in Europe, firms are criminally liable for crimes committed by their employees within the scope of the firm and to its benefit. The nature of corporate crime comprises essentially fraud (usually against the government), environmental violations, and antitrust violations (Cohen, 1996).

Corporate criminal liability puts a serious challenge to the economics of enforcement. Are corporate crimes different from other crimes? Are these crimes best deterred by punishing individuals, punishing corporations, or both? What is optimal structure of sanctions? Should corporate liability be criminal or civil?

This paper has two major contributions to the literature. First, it provides a common analytical framework to most results presented and largely discussed in the field. In second place, by making use of the framework, we provide new insights into how corporations should be punished for the offenses committed by their employees.

Evidence suggests that wrongdoing by corporations is largely an agency cost. It appears to be the case that the managers do not commit corporate crimes to serve the interests of the shareholders (Alexander and Cohen, 1996 and 1999). Thus, the usual economic model of crime needed to be extended to a principal and agent framework in order to explain corporate crime.

Even though the economic analysis of crime is now over 30 years old, Becker's (1968) analysis of optimal punishment has only recently been applied to corporate crime. While most of the literature surveyed in Polinsky and Shavell (2000) has been concerned with optimal sanctioning of rational individuals, recent theoretical analysis has focused on employee-manager relationship. Given the existence of different interests, one aims at designing the appropriate incentives to deter offenses. Under an optimal design, it is useful to discuss if it is desirable to hold an employee liable for corporate crimes (Polinsky and Shavell, 1993; Shavell, 1997), or what the structure of optimal corporate sanctions should be (Arlen, 1994).

In Becker's model, an offense is committed by a rational individual who decides whether or not to commit the crime based on the probability and

severity of punishment. However, in the context of corporations or organi- 
zations, the crime results from different possible actors committing or preventing offenses. Thus, the results presented in Polinsky and Shavell (2000) must be reinterpreted in the context of corporate crime.

Corporate crime is not committed by firms, as such, but by different individuals within the corporation, who are eventually criminally liable. A socially optimal criminal sanctioning policy would favor large corporate fines over criminal liability (and jail sentences) for these individuals involved in the criminal activity (Cohen, 1996). This claim, based on Becker's analysis, assumes that corporate directors and shareholders who could be subject to large fines will provide the correct amount of employee monitoring, and eventually ex post sanctions on their employees to ensure that socially harmful offenses are not committed. In a perfect world, with complete contracting and without liquidity constraints, individual liability alone would induce efficient behavior. Consequently, corporate liability would not be necessary (Arlen, 1999). Conversely, corporate liability is worthwhile investigating when contracts are incomplete or when solvency matters.

Imposing non-monetary sanctions (e.g., imprisonment sentences) is a partial solution to the problem of agents' insufficient wealth. Imprisonment however is expensive and usually courts are not willing to impose them (Arlen and Kraakman, 1997). Thus, corporate liability is the other possible solution.

Corporate liability can take the form of strict liability imposed whenever a crime takes place; duty-based liability imposed only the firm itself violates a legal duty; or a composite regime in which the firm is liable but the magnitude of the sanction depends on whether the firm complied with its duties (Arlen, 1999). Vicarious liability is the strict liability of a principal or the firm for the misconduct of an agent or an employee. Most corporate liability for torts, and in the United States for crimes as well, is vicarious (Kraakman, 1999).

Within a context of corporate liability, shareholders become quasi-enforcers. Since corporations are held strictly liable for their employees' actions, the government delegates on the corporation the task of monitoring and controlling potential offenders (Baysinger, 1991). It lowers the cost of enforcement to the government, but it increases the monitoring costs to firms. Moreover, the government must make sure the firm has the appropriate incentives to monitor and penalize its employees.

The principal-agent setup is the usual framework to study this problem, 
where the government is the principal, the shareholders are the supervisors, and the employees are the agents. Note in passing that most of the literature characterizes the problem as the corporation being the principal and the employees the agents. Our characterization seems more appropriate and more useful as discussed later.

One important question is which party (the government or firm) is the least-cost enforcer. It could be the case that imposing individual criminal liability might be less expensive than imposing high monitoring costs on firms. However, the standard case for corporate liability points out that firms have better information, thus providing less expensive preventive measures. As Arlen and Kraakman (1997) characterize, a firm could be 'superior sanctioner' because their enforcement measures are more credible and effective.

The second important point is how the firm might align the interests of its employees with its own. In particular, the analysis depends on whether or not the firm has the ability to provide correct incentives. Corporate and individual sanctions are substitutes in order to deter crime as long as the employee can bear the full cost of the optimal monetary fine. If the penalty is imposed on the firm, it will be passed along to its employees by lowering salaries. When the firm is unable to shift the penalty to the employee, the penalty should be placed directly on the employee and the corporation must monitor the employee's action to prevent the occurrence. ${ }^{1}$

Aligning the interests of the corporation with those of the government is also expensive (Block, 1991; Alexander and Cohen, 1999). The general result seems to be that poorly performing corporations are more likely to engage in crime (Macey, 1991). Alexander and Cohen (1996) also find that larger firms are more likely to engage in crime than smaller firms. Weak internal controls and concern with short-term financial arrangements, and less concern with long run portfolio diversification, seem to be positively related to corporate crime (Baysinger, 1991). Consequently, performance and dimension of the firm affect the government's cost in monitoring the corporation.

Inducing optimal monitoring and ensuring internal sanctioning (that is, credibility of firm's enforcement policy) is not immune to controversy. Arlen (1994) identifies a 'potentially perverse effect' by which holding firms (vicari-

\footnotetext{
${ }^{1}$ Cohen (1996) finds that sanctions increase with harm and increased individual liability when the organization cannot afford to pass along to its employees the fine.
} 
ously) liable for offenses committed by its employees can increase enforcement costs. If the information that the firm acquires can be used to increase its own probability of incurring liability, the firm will not monitor optimally. In order to tackle this effect, a composite liability regime where some duty-based liability or mitigation provisions are included has been proposed (Arlen, 1994; Arlen and Kraakman, 1997). ${ }^{2}$ However, it has been noted when information costs are high, strict liability could be preferable. ${ }^{3}$

The role of risk aversion is not explicitly considered in our paper. Portfolio diversification means shareholders behave as if they were risk neutral, whereas managers are risk averse. Criminal liability increases the risk of projects, making managers less willing to take them. However, because shareholders are risk neutral, they should be more willing to accept projects that involve criminal offenses, ceteris paribus. These observations suggest that managers should be pushed by shareholders to take projects that involve criminal offenses. Corporation criminal liability would be justified as a device to deter this type of behavior by shareholders (Macey, 1991). Clearly there is an inconsistency with empirical evidence (Romano, 1991): Managers do not commit corporate crimes to serve the interests of the shareholders

Our paper is organized the following way: the basic model is presented in section two, while sections three (moral hazard), four (reputation loss), five (internal punishment), and six (internal control) consider different extensions. Final remarks are addressed in section seven.

\section{Basic Model}

The underlying results of the literature come from the principal-agent model in which the firm's choice of compensation contract affects the agent's choice of care in avoiding crime. In that respect, our model draws on Alexander and Cohen (1999) and Gans (2000).

\footnotetext{
${ }^{2}$ Duty-based liability is imposed only when the firm itself violates a legal duty, and not whenever a crime occurs as in strict liability.

${ }^{3}$ An important extension of corporate criminal law is the potential use of secondary liability beyond the firm. In particular, liability of 'gatekeepers' as a third party monitoring the corporation could be useful. Examples include criminal liability of auditors and lawyers.
} 
Suppose that equity depends on two sort of activities, one being the usual productive effort $(m)$ and the other a socially harmful behavior, e.g. violation of some environmental regulations $(n)$. The expected value of management's equity is given by $\alpha G(m, n)$, where $\alpha$ is the fraction of outstanding equities securities that management owns and $G($.$) is the expected value of firm$ equity.

Equity is determined the following way: it is one with probability $m+n$ and zero with probability $1-m-n$. Thus, the expected value of equity is $G(m, n)=m+n$.

The expected private value of management's socially harmful behavior is $E(n)$, where $E_{n}>0$ and $E_{n n}<0$. Management's effort cost is $C(n, m)$, where $C_{n}>0, C_{m}>0, C_{n n}>0, C_{m m}>0$, and $C_{m n}>0$.

While $n$ denotes the management's influence over the probability that corporate crime will occur, let $u$ be an independent random influence variable with distribution function $F($.$) . Assuming n$ and $u$ have additive effects, social damage occurs if and only if $n+u>0$. Thus, the probability of social damage being observed is $\operatorname{Pr}(n+u>0)=1-F(-n)=P(n)$, the probability of crime being continuously increasing in $n, P_{n}>0$ and $P_{n n} \geq 0$.

It is assumed that the government cannot actually observe $n$. However, if the social bad occurs, the government can, with probability $\sigma$, detect the agent's harmful activity and punish accordingly. Management bears, in that event, a penalty $s_{a}$ while the employer bears a penalty $s_{p}$.

The fixed component of the salary of the management is $\omega$. The expected profits of the (risk neutral) management are:

$$
U=\omega+\alpha(m+n)+E(n)-C(n, m)-P(n) \sigma s_{a}
$$

The expected profits of the owners of the firm are:

$$
V=(1-\alpha)(m+n)-\omega-P(n) \sigma s_{p}
$$

The optimal contract when the employer can observe $m$ and $n$ is described by maximizing the expected profits of the owners of the firm subject to the participation constraint, $U \geq k$, where $k$ is the agent's reservation utility. Rearranging expected profits, we can write:

$$
V=m+n+E(n)-C(n, m)-P(n) \sigma\left(s_{a}+s_{p}\right)-k
$$


The first-order conditions of the problem are:

$$
\begin{gathered}
V_{m}=1-C_{m}=0 \\
V_{n}=1+E_{n}-C_{n}-P_{n} \sigma\left(s_{a}+s_{p}\right)=0
\end{gathered}
$$

Since second-order conditions are satisfied, we derive the optimal contract $\left\langle m^{*}, n^{*}\right\rangle$. The socially harmful activity is decreasing in the policy parameters $\left\langle\sigma, s_{a}, s_{p}\right\rangle$, whereas the productive effort is increasing in those same parameters (because $C_{m n}>0$ ).

As in the usual framework (Polinsky and Shavell, 2000), we consider social welfare to be the sum of the payoffs of the employer and of the management minus the social damage caused by the socially harmful activity. Social welfare is given by:

$$
W=m+n+E(n)-C(m, n)-P(n) H-k
$$

where $H$ is social harm. Notice that the difference between the government's objective and the employer's is the social damage. By setting $s_{a}+s_{p}=$ $H / \sigma$, the government can make the employer's objective identical to its own. Nevertheless this is not a first best outcome because enforcement is costly (Becker, 1968).

It is not very relevant who is actually punished since management and employer can bargain ex ante and reallocate sanctions. It is equally effective to set $s_{a}=H / \sigma$ and $s_{p}=0$ or $s_{p}=H / \sigma$ and $s_{a}=0$. Furthermore, individual liability of management alone induces efficient behavior.

Corporate liability is not needed or necessary unless there is a wealth constraint that limits $s_{a}$. Suppose there is a binding liquidity constraint so that $s_{a}=\bar{\omega}<H / \sigma$. Then, we should have $s_{p}=H / \sigma-\bar{\omega}$ to fully internalize social damage. Corporate liability is justified on the grounds that managers do not have enough wealth to pay for social damage (Polinsky and Shavell, 1993; Shavell, 1997).

In our model, the principal is the government, not the corporation. The corporation and its management team are the agents. There is virtually no distinction between corporation and management because their interests can be aligned at no cost. Once the alignment of interests is costly, the manager is the agent, but the corporation becomes a supervisor or a quasi-enforcer. 


\section{Model with moral hazard}

Suppose the employer cannot observe what sort of activities generated any realized profit. Let us restrict our attention to linear wage contracts. The first-order conditions of the problem for management are:

$$
\begin{gathered}
U_{m}=\alpha-C_{m}=0 \\
U_{n}=\alpha+E_{n}-C_{n}-P_{n} \sigma s_{a}=0
\end{gathered}
$$

Since second-order conditions are satisfied, we derive the agent's choice of effort $\langle\hat{m}, \hat{n}\rangle$.

The optimal contract when the employer cannot observe $m$ and $n$ is described by maximizing the expected profits of the owners of the firm subject to the participation constraint, $U \geq k$, and to the incentive compatibility constraint, $\langle\hat{m}, \hat{n}\rangle$. Rearranging expected profits, we can write:

$$
V=\hat{m}+\hat{n}+E(\hat{n})-C(\hat{n}, \hat{m})-P(\hat{n}) \sigma\left(s_{a}+s_{p}\right)-k
$$

The first-order condition of the problem is:

$$
V_{\alpha}=V_{m} \hat{m}_{\alpha}+V_{n} \hat{n}_{\alpha}=0
$$

where

$$
\begin{aligned}
V_{m} & =1-C_{m}(\hat{m})=1-\alpha \\
V_{n} & =1+E_{n}(\hat{n})-C_{n}(\hat{n})-P_{n}(\hat{n}) \sigma\left(s_{a}+s_{p}\right) \\
& =1-\alpha-P_{n}(\hat{n}) \sigma s_{p}
\end{aligned}
$$

Let us ignore the sanctions for a moment. It is straightforward that we can delegate the optimal effort plan by setting $\alpha=1$. That is hardly surprising in this framework since both employer and management are risk neutral.

A similar conclusion is derived if $s_{p}=0$. In other words, when corporations are not liable for agent's behavior, the optimal contract can be delegated in the presence of moral hazard.

Suppose now that $s_{p}>0$. Setting $\alpha=1$ leads to too much socially harmful activity because management ignores the sanction borne by the employer. 
Thus, the employer chooses $\alpha<1$ to reduce liability, but at the same time, diminishes productive effort (Gans, 2000).

Corporate liability distorts incentives inside the corporation. From a policy view, in this context, corporate liability should not be introduced. Thus, from the set of possible policies we have considered before, we should have $s_{a}=H / \sigma$ and $s_{p}=0$.

Consider again a binding liquidity constraint so that $s_{a}=\bar{\omega}<H / \sigma$. Then, we need $s_{p}=H / \sigma-\bar{\omega}$ to fully internalize the externality. Management's limited wealth generates the need of corporate liability to internalize social damage. However, note that there is a loss of efficiency because of incentives being distorted. As a consequence, the policy should be to fix corporate liability such that $0<s_{p}<H / \sigma-\bar{\omega}$. In general, the social damage in not

fully internalized because of the loss of efficiency due to the distortion of incentives (Polinsky and Shavell, 1993).

\section{Model with reputational sanctions}

Suppose the employer suffers a loss of reputation if found liable for involvement in socially harmful activities. Denote this loss of reputation by a monetary measure $\lambda$. The agent's choice of effort $\langle\hat{m}, \hat{n}\rangle$ is the same as before since nothing changed for the agent.

The optimal contract is described as before by maximizing the expected profits of the owners of the firm subject to the participation constraint, $U \geq k$, and to the incentive compatibility constraint, $\langle\hat{m}, \hat{n}\rangle$. Rearranging expected profits, we can write:

$$
V=\hat{m}+\hat{n}+E(\hat{n})-C(\hat{n}, \hat{m})-P(\hat{n}) \sigma\left(s_{a}+s_{p}+\lambda\right)-k
$$

Notice that the loss of reputation $\lambda$ plays the role of a penalty.

The first-order condition of the problem is:

$$
V_{\alpha}=V_{m} \hat{m}_{\alpha}+V_{n} \hat{n}_{\alpha}=0
$$

where

$$
V_{m}=1-C_{m}(\hat{m})=1-\alpha
$$




$$
\begin{aligned}
V_{n} & =1+E_{n}(\hat{n})-C_{n}(\hat{n})-P_{n}(\hat{n}) \sigma\left(s_{a}+s_{p}+\lambda\right) \\
& =1-\alpha-P_{n}(\hat{n}) \sigma\left(s_{p}+\lambda\right)
\end{aligned}
$$

Within our discussion before, it is easy to see that we cannot delegate the optimal effort plan even if $s_{p}=0$ (unless of course $\lambda=0$ ). From a social viewpoint, we should have $s_{a}=H / \sigma$ and $s_{p}=-\lambda$ to guarantee efficient incentives and full internalization of social harm. Not only sanctioning the employer distorts incentives, but the government should bear the cost of reputation losses (by subsidizing corporations) to make sure the optimal effort plan is chosen. Setting the employer's sanction to zero is not enough because the principal still bears a reputation loss. Indeed corporate liability creates inefficiency because of reputation loss even if the monetary penalty paid to the government is relatively low.

Suppose there is a binding wealth constraint on the agent. We know already that $s_{a}=\bar{\omega}$, but the government should be careful in setting the sanction of the employer. If the loss of reputation is ignored, there will be over-deterrence (Lott, 1996). In other words, by setting $s_{p}=H / \sigma-\bar{\omega}$, there is over-deterrence because the corporation actually suffers $s_{p}+\lambda$. Consequently, we should consider $s_{p}=H / \sigma-\bar{\omega}-\lambda$ to assure full internalization of social damage. Nevertheless, as before, there is a trade-off between full internalization of social damage and efficient incentives. Thus, we should have $-\lambda<s_{p}<H / \sigma-\bar{\omega}-\lambda$ to avoid over-deterrence and find the optimal response to the trade-off between full internalization of social damage and efficient incentives.

\section{Model with internal punishment}

Suppose the employer can apply an internal punishment in the form of a monetary penalty if the socially harmful activity is detected by the government. Denote such penalty by $s_{i}$. The first-order conditions of the problem for management are now:

$$
\begin{gathered}
U_{m}=\alpha-C_{m}=0 \\
U_{n}=\alpha+E_{n}-C_{n}-P_{n} \sigma\left(s_{a}+s_{i}\right)=0
\end{gathered}
$$


Since second-order conditions are satisfied, we derive the agent's choice of effort $\langle\hat{m}, \hat{n}\rangle$.

The optimal contract is described as before by maximizing the expected profits of the owners of the firm subject to the participation constraint, $U \geq k$, and to the incentive compatibility constraint, $\langle\hat{m}, \hat{n}\rangle$. Rearranging expected profits, we can write again:

$$
V=\hat{m}+\hat{n}+E(\hat{n})-C(\hat{n}, \hat{m})-P(\hat{n}) \sigma\left(s_{a}+s_{p}\right)-k
$$

Note that the internal penalty $s_{i}$ disappears from $V$ because the fixed salary $\omega$ exactly compensates for the expected internal penalty (by solving the participation constraint).

The first-order conditions of the problem are:

$$
\begin{gathered}
V_{\alpha}=V_{m} \hat{m}_{\alpha}+V_{n} \hat{n}_{\alpha}=0 \\
V_{s_{i}}=V_{m} \hat{m}_{s_{i}}+V_{n} \hat{n}_{s_{i}}=0
\end{gathered}
$$

where

$$
\begin{aligned}
V_{m} & =1-C_{m}(\hat{m})=1-\alpha \\
V_{n} & =1+E_{n}(\hat{n})-C_{n}(\hat{n})-P_{n}(\hat{n}) \sigma\left(s_{a}+s_{p}\right) \\
& =1-\alpha-P_{n}(\hat{n}) \sigma\left(s_{p}-s_{i}\right)
\end{aligned}
$$

It is easy to see that we can delegate the optimal effort plan by setting $\alpha=1$ and $s_{i}=s_{p}$. As long as management pays for the employer's sanction, the best solution can be achieved. Corporate liability becomes less important if an internal penalty system can be designed so that management bears the liability loss.

One problem with internal punishment is that there are legal limitations to employer's ability to control management. Suppose these constraints are binding so that $s_{i}=\bar{s}<s_{p}$. Then, we have $\alpha<1$ for the reasons discussed before, that is, by reducing liability costs, the employer also reduces productive effort. The optimal effort plan cannot be delegated.

From the government's viewpoint, any policy where $s_{p} \leq \bar{s}$ and $s_{a}=$ $H / \sigma-s_{p}$ is equally effective. Corporate liability does not play a major role 
as long as the government recognizes the internal penalty as a mechanism to achieve efficient incentives (Shavell, 1997).

Consider again the possibility of a binding wealth constraint on the agent. It must be the case that $s_{a}+s_{i} \leq \bar{\omega}$. In order to assure optimal effort, we should have $s_{i}=s_{p}$, which implies $s_{a}+s_{p} \leq \bar{\omega}$. The problem of course is that because $\bar{\omega}$ is less than $H / \sigma$, the social damage is not internalized. Recall that full internalization of the social damage implies $s_{a}+s_{p}=H / \sigma$. Given the wealth constraint, to assure full internalization it is necessary the case that $s_{i}<s_{p}$, that is, the optimal effort plan is not delegated because incentives are distorted.

The design of enforcement policy must take into account that, in absence of restrictions on internal punishment, the corporation will set $s_{i}=\bar{\omega}-s_{a}$. By setting $s_{a}=\bar{\omega}$, the corporation cannot apply an internal punishment scheme (since management cannot pay for it), and $s_{i}=0$. In this situation incentives are highly distorted inside the firm. Thus, in general, the policy will be described by $0<s_{a}<\bar{\omega}$ and $0<s_{p}<H / \sigma-s_{a}$ as a response to the trade-off between internalization of social damages and appropriate incentives inside the corporation.

Notice that if $s_{a}=\bar{\omega}$, the policy is described as in the simple model with moral hazard, making no use of internal punishment. By reducing $s_{a}$, the corporation can make use of internal punishment and improve incentives inside the firm. However, a reduction of $s_{a}$ asks for an increase of $s_{p}$ to offset the negative effect on the internalization of social damage. Nevertheless, an increase of $s_{p}$ distorts incentives inside the corporation. Thus, the government might not want to increase $s_{p}$ and accept less internalization of social damage than otherwise, but more efficient incentives.

\section{Model with internal control}

The model so far presented is one of corporate strict liability, where the punishment of the corporation $s_{p}$ is applied once the socially harmful activity is detected by the government. In this version of the model, we extend the analysis to internal control and consider a composite liability regime with some duty-based liability. 
Consider that the corporation has the possibility of introducing an internal control device: Management is audited and detected with probability $\rho$ by the employer. If detected by the employer, management will be reported to the government. The probability of being detected by the government if detected by the employer is one because the corporation acts as a quasi-enforcer. ${ }^{4}$ If management is not detected by the employer, there is a probability $\sigma$ of being detected by the government. The sanction imposed on the agent is $s_{a}$. The sanction imposed on the employer is $s_{q}$ if management is detected by the corporation, and $s_{p}$ if management is detected by the government. The difference $s_{p}-s_{q}$ could be interpreted as corporate liability mitigation for introducing internal control mechanisms. The cost for the employer to set such internal control device is $T(\rho)$, where $T^{\prime}>0$ for $\rho>0, T^{\prime}(0)=0$, and $T^{\prime \prime}>0$.

The expected profits of the (risk neutral) management are:

$$
U=\omega+\alpha(m+n)+E(n)-C(n, m)-P(n)[\sigma+(1-\sigma) \rho] s_{a}
$$

For a given $\sigma$, the likelihood of management being detected is higher when an internal control mechanism is adopted. The first-order conditions of the problem for management are:

$$
\begin{gathered}
U_{m}=\alpha-C_{m}=0 \\
U_{n}=\alpha+E_{n}-C_{n}-P_{n}[\sigma+(1-\sigma) \rho] s_{a}=0
\end{gathered}
$$

Since second-order conditions are satisfied, we derive the agent's choice of effort $\langle\hat{m}, \hat{n}\rangle$.

The optimal contract is described as before by maximizing the expected profits of the owners of the firm subject to the participation constraint, $U \geq k$, and to the incentive compatibility constraint, $\langle\hat{m}, \hat{n}\rangle$. Rearranging expected profits, we can write again:

$V=\hat{m}+\hat{n}+E(\hat{n})-C(\hat{n}, \hat{m})-P(\hat{n})\left[\rho\left(s_{a}+s_{q}\right)+(1-\rho) \sigma\left(s_{a}+s_{p}\right)\right]-T(\rho)-k$

The 'perverse effect' of adopting internal control mechanisms is exposed by comparing the expected sanction $\rho\left(s_{a}+s_{q}\right)$ with $\sigma(1-\rho)\left(s_{a}+s_{p}\right)$. Employer's

\footnotetext{
${ }^{4}$ We discuss later the possibility that the corporation may renege on its enforcement responsibilities.
} 
monitoring and detection activities generate compromising evidence that can make conviction easier. Setting $s_{q}<s_{p}$ is not enough to make sure that the employer does really prefer an internal control device for two reasons. First, even though the sanction is lower, the likelihood of paying it could be high enough to offset the first effect (Arlen, 1994). Second, the employers bears the sanction paid by the agent (because of the participation constraint), and the agent is fined with a higher probability when there is internal control.

The first-order conditions of the problem are:

$$
\begin{gathered}
V_{\alpha}=V_{m} \hat{m}_{\alpha}+V_{n} \hat{n}_{\alpha}=0 \\
V_{\rho}=V_{m} \hat{m}_{\rho}+V_{n} \hat{n}_{\rho} \\
-P(\hat{n})\left[(1-\sigma) s_{a}+s_{q}-\sigma s_{p}\right]-T^{\prime}=0
\end{gathered}
$$

where

$$
\begin{aligned}
V_{m} & =1-C_{m}(\hat{m})=1-\alpha \\
V_{n} & =1+E_{n}(\hat{n})-C_{n}(\hat{n})-P_{n}(\hat{n})\left[\rho\left(s_{a}+s_{q}\right)+(1-\rho) \sigma\left(s_{a}+s_{p}\right)\right] \\
& =1-\alpha-P_{n}(\hat{n})\left[\rho s_{q}+(1-\sigma) \rho s_{p}\right]
\end{aligned}
$$

It is easy to see that we cannot delegate the optimal effort as long as at least one of $s_{p}$ or $s_{q}$ is positive (as long as there is corporate liability). From social welfare viewpoint, by setting:

$$
\rho\left(s_{a}+s_{q}\right)+(1-\rho) \sigma\left(s_{a}+s_{p}\right)=H
$$

the government can make the employer's objective identical to its own. One possibility is to set $s_{p}=s_{q}=0$ and $s_{a}=H /[\rho+(1-\rho) \sigma]$. Given that both the government and the employer have the same objective function, the decision of introducing an internal control mechanism taken by the employer is socially optimal. Clearly in this case the corporation never adopts an internal mechanism control since there is no corporate liability.

We consider a binding wealth constraint to generate more interesting results. Suppose $s_{a}=\bar{\omega}$. Full internalization of social damage is guaranteed by solving:

$$
\rho s_{q}+(1-\rho) \sigma s_{p}=H-\bar{\omega}[\rho+(1-\rho) \sigma]
$$


It is important to note that the right-hand-side of (26) is decreasing in $\rho$. With an internal control mechanism, full internalization of social damage when management has a wealth constraint can be achieved with a lower expected sanction for the employer. Consider a very effective internal system where management is detected with probability one. Full internalization of social damage requires the sanction $s_{q}=H-\bar{\omega}$ which is less than the sanction derived in section three, $s_{p}=H / \sigma-\bar{\omega}$, when there is no internal control. It confirms that full internalization of social damage can be achieved with a lower sanction for the employer.

When social damage is fully internalized, the government and the corporation have the same objective function. By construction, the employer would choose the socially optimal internal control mechanism since both employer and government have the same objective function. But we already know that the consequence is that incentives will be distorted inside the corporation (due to the fact that $\alpha<1$ ).

The distortion of incentives which has been explained in section three implies that generally we will have:

$$
\rho s_{q}+(1-\rho) \sigma s_{p}<H-\bar{\omega}[\rho+(1-\rho) \sigma]
$$

The implication is that the objective function of the employer is no longer that of the government. The optimal $\rho$ for the corporation is described by (23). There are three effects to be considered. The last term measures the marginal cost of introducing an internal mechanism. The first two terms are positive because an internal mechanism generates more efficient incentives (it increases productive effort and reduces the socially harmful activity). The third term measures the marginal gain for the corporations from introducing an internal control mechanism in terms of being sanctioned. The so-called 'potentially perverse effect' is measured by the marginal gain $\sigma s_{p}-s_{q}-(1-$ $\sigma) \bar{\omega}$.

Suppose $\sigma s_{p}-s_{q}-(1-\sigma) \bar{\omega}<0$, that is, the third tem in (23) is positive. In our model, this corresponds to the so-called 'potentially perverse effect' (Arlen, 1994). Liability costs are increased for the corporation, and so the employer will be less willing to invest on an internal control device. The reason would be that even though an internal mechanism control improves incentives inside the corporation, it increases liability and enforcement costs. 
Note that if incentives were efficient, an employer would always reject an internal control mechanism.

From the policymaker viewpoint, the corporation's choice of $\rho$ would be socially optimal when the third term is zero. ${ }^{5}$ Consequently, the policymaker should set:

$$
s_{q}=\sigma s_{p}-(1-\sigma) \bar{\omega}
$$

The liability mitigation differential is justified on the basis that it makes the employer's choice of an internal control mechanism socially optimal. In general, we should expect $s_{q}<0$, that is, the corporation should be compensated for introducing the (socially optimal) internal control device.

When the corporation is a 'superior sanctioner,' the cost $T^{\prime}$ will be reasonably low whereas the probability $\rho$ will be high enough. The government prefers corporate liability with an internal mechanism. However, if the government is a 'superior sanctioner,' the cost $T^{\prime}$ will be large and the probability $\rho$ will be low. It is better to have corporate liability without relying too much on an internal control mechanism (Arlen and Kraakman, 1997).

One possible problem with an internal mechanism is the incentive for the corporation to renegade on its enforcement responsibilities, settle with management a private deal, and not report to the government. One possible way to avoid the problem is having the government auditing the corporation making sure the employer does not renege on enforcement commitments. This governmental auditing makes an internal control mechanism more expensive, and eventually less appealing. The alternative way is for the government to pay a compensation for the employer. Let us show that the solution we propose is collusion-proof.

By informing the government, the employer loses $s_{q}$, whereas by not informing, the employer faces a sanction $s_{p}$ with probability $\sigma$. Management pays $s_{a}$ if the employer reports, whereas faces a sanction $s_{a}$ with probability $\sigma$ if the employer does not report. The maximum payment management is willing to make is $s_{a}(1-\sigma)$. The payoff of employer by reporting is $-s_{q}$ whereas the expected payoff by withholding evidence is $s_{a}(1-\sigma)-\sigma s_{p}$. Taking $s_{q}$ as shown in (28), we have that both payoffs are the same, making

\footnotetext{
${ }^{5}$ From maximizing $W$ with respect to $\rho$, it is immediate that the first-order condition is similar to (23) when the third term is zero.
} 
collusion not possible. The corporation has no incentive to renege on its enforcement responsibilities.

In conclusion, the policy would be to set $s_{q}=\sigma s_{p}-(1-\sigma) \bar{\omega}$ and $0<$ $s_{p}<H / \sigma-\bar{\omega}$. The sanction $s_{q}$ assures that an internal control mechanism is socially optimal. The sanction $s_{p}$ is determined by the optimal response to the trade-off between fully internalizing social damage and designing efficient incentives.

\section{Conclusion}

Our paper has reviewed the economic model of corporate criminal law within a unified framework. We offer new insights, in particular, we extensively discuss the role of moral hazard and liquidity constraints in creating the need for corporate liability.

The critique of corporate criminal liability versus civil penalties proceeds on three fronts. First, Fischel and Sykes (1996) note that incarceration is unavailable against corporations and makes little sense in the context of corporate liability. Even though it might appear to reduce the insolvency problem caused by imposing very high fines, it will impose additional nonmonetary sanctions, such as stigma. Karpoff and Lott (1993), Khanna (1996) and Lott (1996) argue that corporate criminal sanctions have an associated reputational loss absent on civil penalties. The loss of reputation could overpenalize corporations (Alexander, 1999).

The second critique refers to the fact that corporate penalties do not aim at conventional deterrence, but at monitoring, leading to over-deterrence (Fischel and Sykes, 1996; Parker, 1996). When a corporation cannot distinguish between good and harmful acts, but can only set incentives based on observed variables, the imposition of criminal liability could dilute incentives and reduce productivity (Gans, 2000). Nevertheless, the empirical effect on management turnover and governance changes does not seem to be very systematic (Agrawal, Jaffe and Karpoff, 1999).

Finally, even though corporate liability could serve a preference-shaping function, other mechanisms could be more efficient, e.g. publicity (Khanna, 1996). 
Our paper shows that corporate criminal liability is useful when agents cannot pay for the social damage their actions cause. Nevertheless, because of the several problems mention above, the sanction borne by the corporation is less than what should be to fully internalize social damage. The paper points out that corporate criminal liability is the solution to a trade-off between internalization of social damage (i.e., socially optimal deterrence) and efficient incentives (due to moral hazard)

Our model suggests that corporate monetary fines should be low, a result with strong empirical evidence (Cohen, 1991). The introduction of corporate criminal sentencing guidelines and the Sentencing Commission's announced intention of raising and restructuring corporate monetary penalties seem to indicate that until 1991 corporate fines were too limited. After 1991, it is of dispute if corporate criminal sentencing plays an important role in the overall public enforcement effort (Alexander, Arlen and Cohen, 1999; Parker and Atkins, 1999)

\section{References}

Agrawal, A., Jaffe, J. F., and Karpoff, J. M., 1999, Management Turnover and Governance Changes following the Revelation of Fraud, Journal of Law and Economics, 42, 309-342.

Alexander, C. R., 1999, On the Nature of Reputational Penalty for Corporate Crime: Evidence, Journal of Law and Economics, 42, 489-526.

Alexander, C. R. and Cohen, M. A., 1996, New Evidence on the Origins of Corporate Crime, Managerial and Decision Economics, 17, 421-435.

Alexander, C. R. and Cohen, M. A., 1999, Why do Corporations Become Criminals? Ownership, Hidden Actions, and Crime as an Agency Cost, Journal of Corporate Finance, 5, 1-34.

Alexander, C. R., Arlen, J. H., and Cohen, M. A., 1999, Regulating Corporate Criminal Sanctions: Federal Guidelines and the Sentencing of Public Firms, Journal of Law and Economics, 42, 393-422.

Arlen, J. H., 1994, The Potentially Perverse Effects of Corporate Criminal Liability, Journal of Legal Studies, 23, 833-867. 
Arlen, J. H., 1999, Corporate Crime and Its Control, in New Palgrave Dictionary of Economics and the Law, edited by P. Newman.

Arlen, J. H., and Kraakman, R., 1997, Controlling Corporate Misconduct: An Analysis of Corporate Liability Regimes, New York University Law Review, 72: 687-779.

Baysinger, B. D., 1991, Organization Theory and the Criminal Liability of Organizations, Boston University Law Review, 71, 341-376.

Becker, G. S., 1968, Crime and Punishment: An Economic Approach, Journal of Political Economy, 76, 169-217.

Block, M., 1991, Optimal Penalties, Criminal Law and the Control of Corporate Behavior, Boston University Law Review, 71, 395-419.

Cohen, M. A., 1991, Corporate Crime and Punishment: An Update on Sentencing Practice in the Federal Courts, Boston University Law Review, 71, 247-280.

Cohen, M. A., 1996, Theories of Punishment and Empirical Trends in Corporate Criminal Sanctions, Managerial and Decision Economics, 17, 399411.

Fischel, D. R. and Sykes, A. O., 1996, Corporate Crime, Journal of Legal Studies, 25, 319-349.

Gans, J., 2000, Incentive Contracts, Optimal Penalties and Enforcement, Melbourne Business School mimeograph.

Karpoff, J. M. and Lott, J. R., 1993, The Reputational Penalty Firms Bear from Committing Criminal Fraud, Journal of Law and Economics, 36, 757-802.

Khanna, V. S., 1996, Corporate Criminal Liability: What Purpose Does It Serve?, Harvard Law Review, 109, 1477-1534.

Kraakman, R. H., 1999, Vicarious and Corporate Civil Liability, in Encyclopedia of Law and Economics, edited by Bouckaert, B. and De Geest, G., Aldershot, Edward Elgar.

Lott, J. R., 1996, The Level of Optimal Fines to Prevent Fraud when Reputation Exist and Penalty Clauses are Unforceable, Managerial and Decision Economics, 17, 363-380. 
Macey, J., 1991, Agency Theory and The Criminal Liability of Organizations, Boston University Law Review, 71, 315-340.

Parker, J. S., 1996, Doctrine for Destruction: The Case of Corporate Criminal Liability, Managerial and Decision Economics, 17, 381-398.

Parker, J. S., and Atkins, R. A., 1999, Did the Corporate Criminal Sentencing Guidelines Matter? Some Preliminary Empirical Observations, Journal of Law and Economics, 42, 423-453.

Polinsky, A. M. and Shavell, S., 1993, Should Employee be Subject to Fines and Imprisonment Given the Existence of Corporate Liability, International Review of Law and Economics, 13, 239-257.

Polinsky, A. M., and Shavell, S., 2000, The Economic Theory of Public Enforcement Law, Journal of Economic Literature, 38, 45-76.

Romano, R., 1991, Theory of the Firm and Corporate Sentencing: Comment on Baysinger and Macey, Boston University Law Review, 71, 377-382.

Shavell, S., 1997, The Optimal Level of Corporate Liability Given the Limited Ability of Corporations to Penalize Their Employees, International Review of Law and Economics, 17, 203-213. 